\title{
Cytogenetic Studies in Some Apareiodon Species (Pisces, Parodontidae)
}

\author{
Célia Maria de Jesus* and Orlando Moreira-Filho \\ Departamento de Genética e Evolução, Universidade Federal de São Carlos Rodovia Washington Luis, \\ km 235, Caixa Postal 676, CEP 13565-905, São Carlos, SP, Brasil \\ Accepted September 8, 2000
}

\begin{abstract}
Summary Cytogenetic studies in 6 species of Apareiodon (Pisces, Parodontidae) from different Brazilian hydrographic basins showed a diploid number equal to $2 n=54$ chromosomes and the absence of morphologically differentiated sex chromosomes. Although the diploid and the fundamental numbers had been constant, some differences were observed concerning the karyotypic structure of the species. A. ibitiensis, Apareiodon sp. A and Apareiodon sp. B presented 50M/SM $+4 \mathrm{ST}$ chromosomes, while A. piracicabae, A. vittatus and Apareiodon sp. C presented 52M/SM+2ST ones. Apareiodon piracicabae showed a polymorphism in relation to the number and position of the nucleolar organizer regions (NORs), while A. vittatus showed a variation in the NORs size. The available data indicate that the Parodontidae family have been submitted to a chromosomal diversification during their species differentiation process, despite the maintenance of the same diploid number.
\end{abstract}

Key words Apareiodon, Karyotypic evolution, NOR, C-band.

The Characiformes fish are widely distributed in the neotropical region, showing a wide variation in the diploid number. Two general trends in the chromosomal evolution can be observed in this order. In fact, some groups show a heterogeneous evolutionary with a diversity in the chromosome number and the karyotypic structure. In contrast, a more homogenous pattern can be observed in other groups, leading to a relatively stable karyotypes. Thus, Prochilodontidae, Anostomidae, Hemiodontidae, Curimatidae and Parodontidae families, have shown few or none variation in respect to the diploid number and the macrokaryotypic structure. On the other hand, Erythrinidae and Characidae have shown a wide numerical and structural variation in their karyotypes (Galetti Jr. et al. 1994). In the present work, 6 species of the Apareiodon genus were studied, with the description and discussion of their karyotypic patterns.

\section{Materials and methods}

Chromosome analyses were performed in six species of the Apareidon genus from different Brazilian hydrographic basins. Some species are still awaiting a more precise identification and were temporarily designated as A, B and C. Apareiodon ibitiensis was collected in the Passa-Cinco river, and $A$. piracicabae in the Passa-Cinco and Mogi-Guaçu rivers, both belonging to upper Paraná basin. Apareiodon sp. A and Apareiodon sp. B were collected in the Frio and Barreiro Grande streams, respectively, both belonging to the São Francisco basin. A. vittatus was caught in the Timbó river, and Apareiodon sp. C in the Araguaia river, belonging to the Iguacu and Araguaia basins, respectively.

Mitotic chromosomes were obtained according to Bertollo et al. (1978). The detection of the nucleolar organizer regions (Ag-NORs), C-banding and the staining with distamycin/chromomycin $\mathrm{A}_{3}\left(\mathrm{DA} / \mathrm{CMA}_{3}\right.$ ), followed the basic procedures of Howell and Black (1980), Sumner (1972) and

\footnotetext{
*Corresponding author, e-mail: pcej@iris.ufscar.br
} 
Schweizer (1980), respectively. The chromosomes were arranged in 2 major groups in the karyotypes - the metacentric/submetacentric (M/SM) and the subtelocentric (ST) ones - and paired in a decreasing order of size.

\section{Results}

All the species showed a diploid number equal to 54 chromosomes and a fundamental number (FN) equal to 108 , both for females and males. Chromosomal sex differences were not found.

(a)

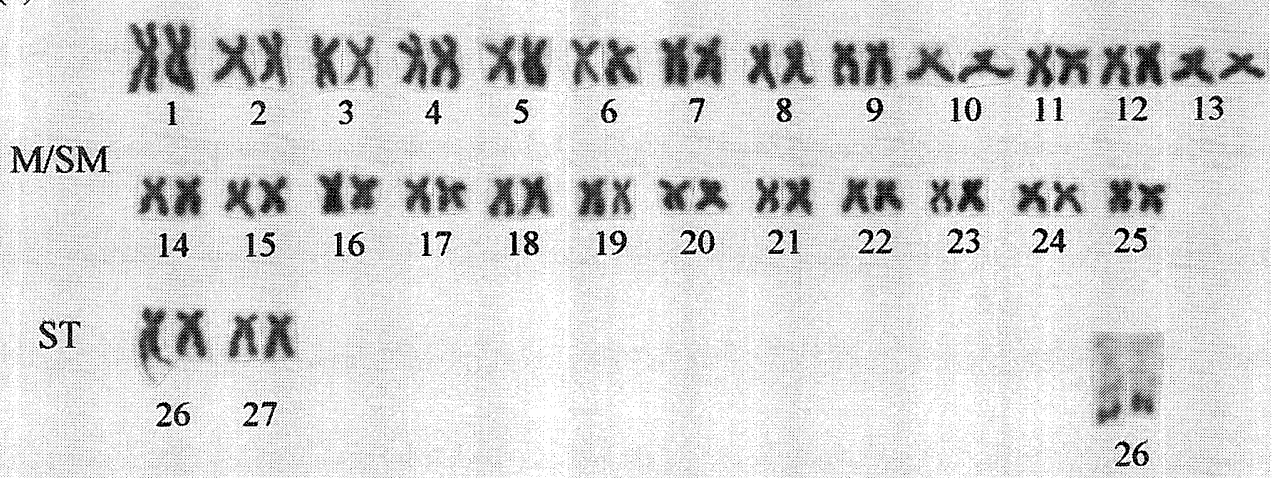

(b)

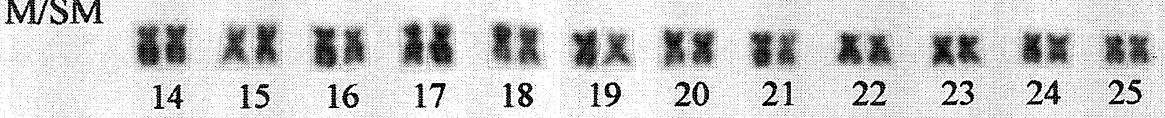

ST EI 11

$26 \quad 27$

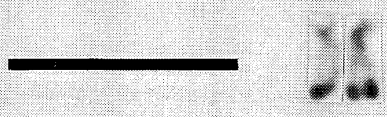

26

(c)

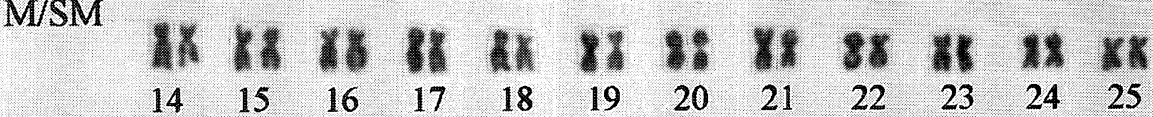
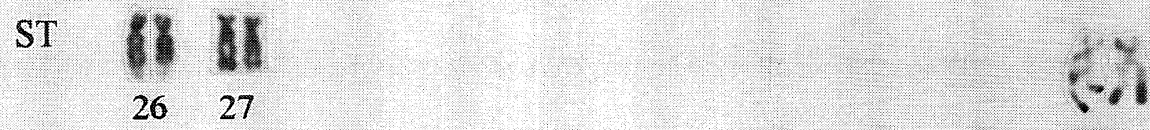

Fig. 1. Giemsa stained karyotypes and NOR-bearing chromosomes (Ag-NORs). a) Apareiodon sp. A, b) Apareiodon sp. B, c) A. ibitiensis., Length bar corresponds to $20 \mu \mathrm{m}$. 
Apareiodon sp. A, Apareiodon sp. B and A. ibitiensis present 25 meta/submetacentric chromosome pairs plus 2 subtelocentric pairs (Fig. 1). A. vittatus, A. piracicabae and Apareiodon sp. C showed 26 meta/submetacentric chromosome pairs plus only one subtelocentric pair (Fig. 2).

The NOR is located in the terminal region of the long arm of a subtelocentric pair, correspondent to the number 26 in the Apareiodon sp. A, Apareiodon sp. B and Apareiodon ibitiensis karyotypes (Fig. 1) and to the number 27 in the A. vittatus karyotype (Fig. 2a). Although A. piracicabae also show the NOR in the subtelocentric pair 27 , inter- and intraindividual variations can be ob-

(a)

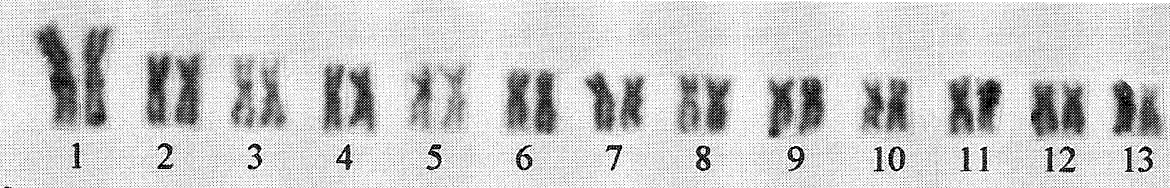

M/SM

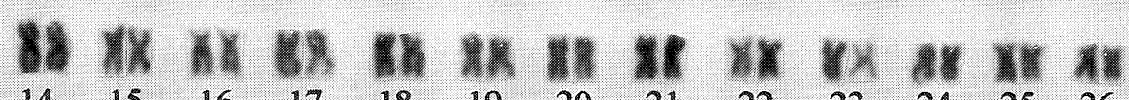

$\begin{array}{lllllllllllll}14 & 15 & 16 & 17 & 18 & 19 & 20 & 21 & 22 & 23 & 24 & 25 & 26\end{array}$

ST

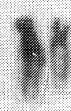

27

(b)
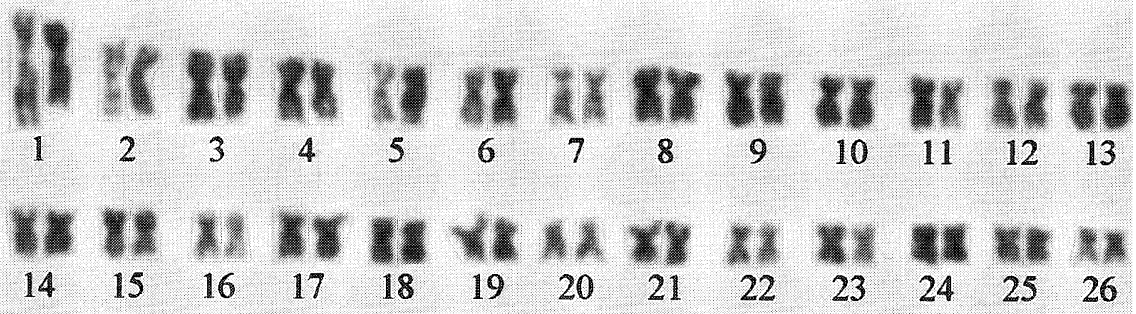

ST

27

(c)

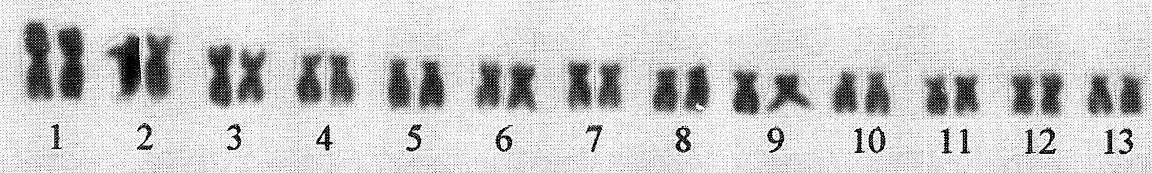

M/SM

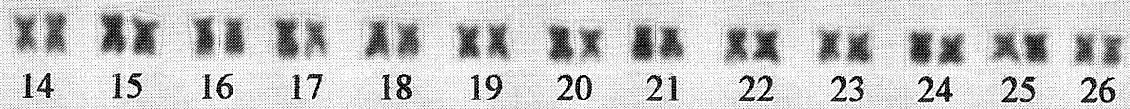

ST 2 :

27

Fig. 2. Giemsa stained karyotypes and NOR-bearing chromosomes (Ag-NORs). a) Apareiodon vittatus, b) A. piracicabae, c) Apareiodon sp. C. Ag-NORs are not showed for A. piracicabae and Apareiodon sp. C. Length bar corresponds to $20 \mu \mathrm{m}$. 
served in relation to its number, position and size, as follows: (a) a double NOR in the 2 homologous chromosomes, (b) a double NOR in only one of the chromosomes of the pair, (c) a large, but undivided NOR in the 2 homologues, (d) a large undivided NOR in a chromosome and a small NOR in the homologue (Fig. 3a-d). Other NOR phenotypes were observed, although with a few frequency: a small NOR in the 2 homologous chromosomes, a large or a small NOR in only one of homologues, the other not showing a NOR and a small interstitial NOR in only one chromosome. Chromomycin $\mathrm{A}_{3}$ stained chromosomes evidenced a correspondent phenotypic pattern to that obtained with silver staining (Fig. 3e-h).

Heterochromatic blocks are seen in the centromeric regions of all chromosomes and also in the telomeric regions of some others, after C-banding (Fig. 4). In A. ibitiensis and Apareiodon sp. B heterochromatin is coincident with the NOR, while in A. piracicabae and Apareiodon sp. A it is adjacent to the NOR.

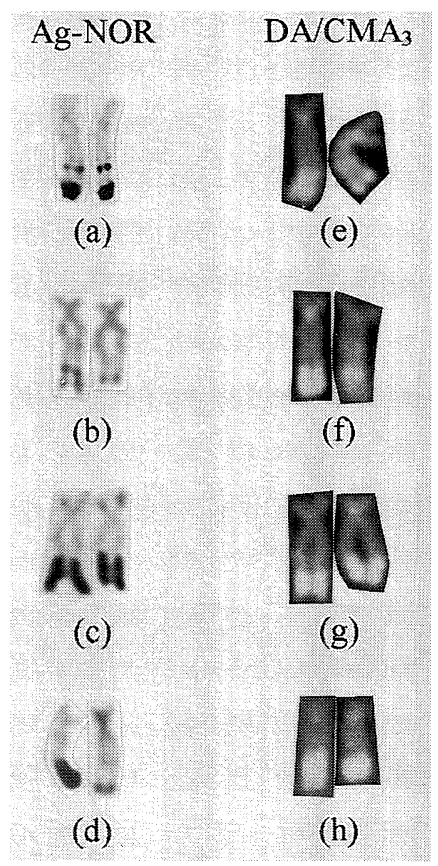

Fig. 3. NOR-bearing chromosomes of Apareiodon piracicabae stained by silver nitrate: Ag-NORs (a-d) and by $\mathrm{DA} / \mathrm{CMA}_{3}(\mathrm{e}-\mathrm{h})$.

\section{Discussion}

Two karyotypic groups can be considered among the analysed species, according to the meta/submetacentric and subtelocentric chromosome numbers: A. ibitiensis, Apareiodon sp. A and Apareiodon sp. B show 50M/SM+4ST and A. piracicabae, A. vittatus and Apareiodon sp. $\mathrm{C}$ show $52 \mathrm{M} / \mathrm{SM}+2 \mathrm{ST}$ chromosomes. In all the species the heterochromatic pattern is conserved, with $\mathrm{C}$ bands preferentially located in the centromeric and some telomeric regions. These results are similar to that described for Apareiodon affinis (Jesus et al. 1999) and Parodon species (Moreira-Filho et al. 1993, Jesus and Moreira-Filho 2000).

NORs were already analysed in seven species of Apareiodon, including the six ones in the present paper (Moreira-Filho et al. 1984, Jorge 1995, Jesus et al. 1999). Except for A. affinis from the Cuiabá river (Jesus et al. 1999) and the low Paraná river (Jorge 1995), that present NORs in both subtelocentric and acrocentric chromosomes, the remaining species show NORs only located in subtelocentric chromosomes. Although A. piracicabae may present a double NOR on the same chromosomal arm, the other species show a single undivided NOR, which probably represents an ancestral condition in the Parodontidae family.

Variation in the size among homologous NOR was also frequently observed, although this fact was more accentuated in A. vittatus. According to Foresti et al. (1981) NORs present a polymorphic nature in fish, which has been confirmed by several other studies in the last years (Phillips et al. 1989, Bertollo and Cavallaro 1992, Galetti et al. 1995, Jesus et al. 1999). This occurrence can result from structural rearrangements in the chromosomes as duplications, deletions, and unequal exchanges (Gold et al. 1990). In particular, A. piracicabae showed an inter- and intraindividual polymorphism regarding the number, position and size of the NORs, where were observed since a single NOR placed in only one of the homologues, until a double NOR placed in both chromosomes of the pair 27 (Fig. 3). Prior studies indicate that the double NOR probably results from a paracentric in- 


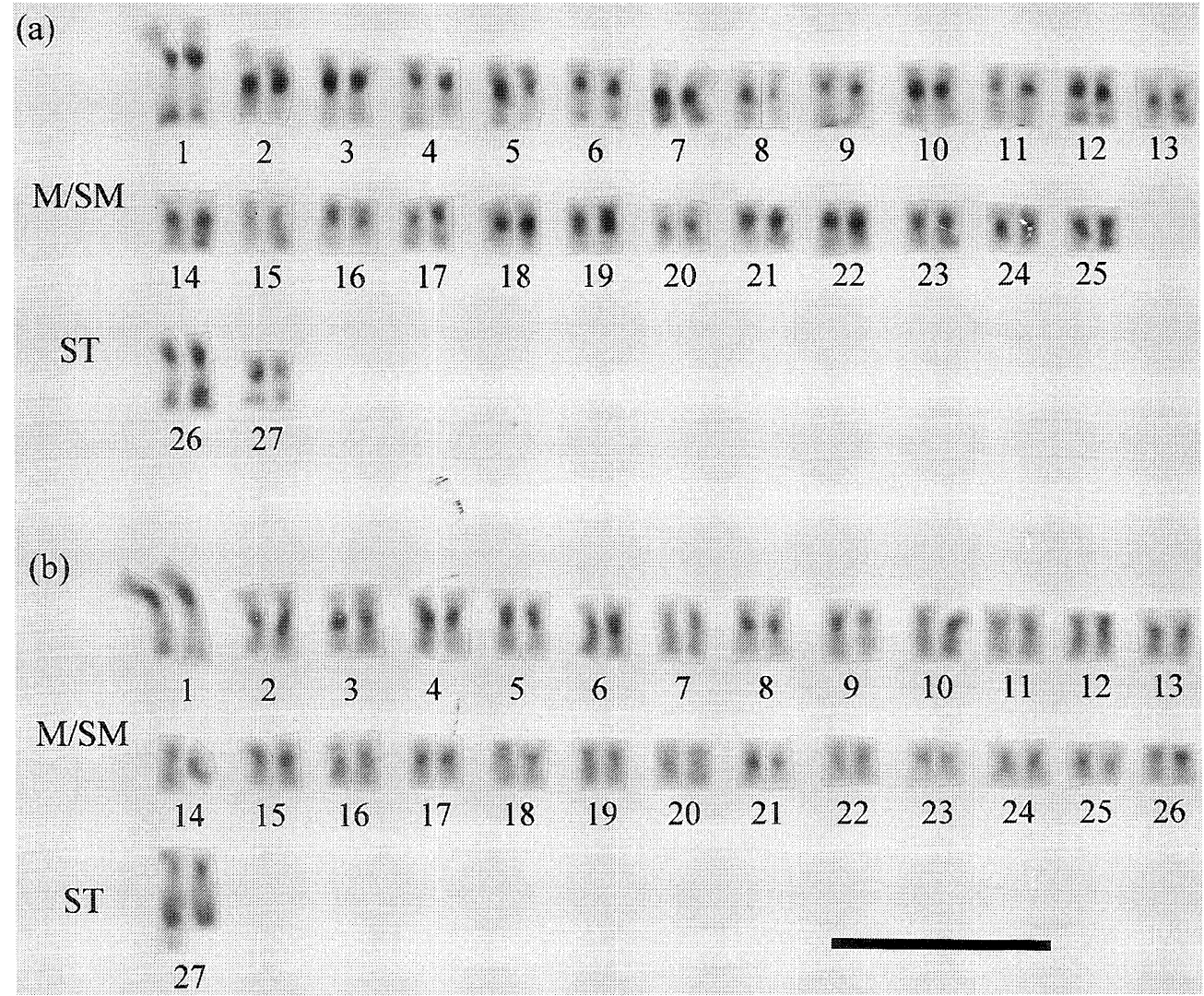

Fig. 4. a) C-banded karyotypes of Apareiodon sp. B, b) A. piracicabae showing the constitutive heterochromatin pattern. Length bar corresponds to $20 \mu \mathrm{m}$.

version in an ancestral chromosome with a heterochromatic region adjacent to a single and terminal NOR, illustrating a derived condition among the Parodontidae (Moreira-Filho et al. 1984).

The species now analysed did not show any evidence of morphologically differentiated sex chromosomes. Nevertheless, distinct sex chromosome systems were already described in 2 Parodontidae species, showing two divergent differentiation process. Thus, in $A$. affinis from the upper Paraná a $\mathrm{ZZ} / \mathrm{ZW}_{1} \mathrm{~W}_{2}$ system appears to be originated through centric fission and pericentric inversions while in $P$. hilarii from the São Francisco basin the differentiation of a ZZ/ZW system was accomplished by a heterochromatinization process (Moreira-Filho et al. 1980, 1993, Jesus et al. 1999).

The present work demonstrates that the prior assumed premise, according to Parodontidae fish show a marked stability in karyotype macrostructure, with little or none variation in relation to the diploid number and chromosomal morphology (Galetti Jr. et al. 1994), is not totally correct. In contrast, the karyotypic evolution of this fish family presents structural divergences among their species. Besides the sex chromosomes differences in $A$. affinis and $P$. hillari, above related, some $A$. affinis populations from Argentina and Cuiabá river (Jorge 1995, Jesus et al. 1999) show a polymorphic system due to pericentric inversions, originating acrocentric chromosomes only observed in these fishes. Moreover, the double NOR system found in $A$. piracicabae and the NOR location on biarmed chromosomes in Parodon sp. and P. hilarii (Jesus and Moreira-Filho 2000) point also to structural rearrangements, as paracentric inversions and translocations, respectively.

Thus, the results thus far obtained indicate for chromosomal divergences in the Parodontidae 
family. Even maintaining a same diploid number, the Parodontidae probably have undergone some different ways of chromosomal diversification in their speciation process.

\section{Acknowledgements}

The authors are grateful to Dr. Yoshimi Sato (CODEVASF) and Dr. Paulo C. Venere (Universidade Federal do Mato Grosso) for supplying fish samples, Dr. Heraldo A. Britski (Museu de Zoologia da USP) for species identification, Dr. Luis A. C. Bertollo (Universidade Federal de São Carlos) for suggestions in the manuscript, and to Instituto Brasileiro do Meio Ambiente e dos Recursos Naturais Renováveis (IBAMA) for authorization in fish captures. This research was supported by Coordenacao de Aperfeiçoamento de Pessoal de Nível Superior (CAPES), Fundação de Amparo à Pesquisa do Estado de São Paulo (FAPESP), and Universidade Federal de Sao Carlos (UFSCar).

\section{References}

Bertollo, L. AC. and Cavallaro, Z. I. 1992. A highly differentiated ZZ/ZW sex chromosome in a Characidae fish, Triportheus guentheri. Cytogenet. Cell Genet. 60: 60-63.

-, Takahashi, C. S. and Moreira-Filho, O. 1978. Cytotaxonomic considerations on Hoplias lacerdae (Pisces, Erythrynidae). Brazil. J. Genet. 1: 103-120.

Foresti, F., Almeida-Toledo, L. F. and Toledo, S. A. F. 1981. Polymorphic nature of nucleolus organizer regions in fishes. Cytogenet. Cell Genet. 31: 137-144.

Galetti Jr., P. M., Bertollo, L. A. C. and Moreira-Filho, O. 1994. Trends in chromosome evolution of neotropical characiform fishes. Caryologia 47: 289-298.

-, Lima, N. R. W. and Venere, P. C. 1995. A monophiletic ZW sex chromosome system in Leporinus (Anostomidae, Characiformes). Cytologia 60: 375-382.

Gold, J. R., Li, C., Shipley, N. S. and Powers, P. K. 1990. Improved methods for working with fish chromosomes with a review of metaphase chromosome banding. J.Fish Biol. 37: 563-575.

Howell, W. M. and Black, D. A. 1980. Controlled silver staining of the nucleolus organizer regions with a protective colloidal developer: a 1-step method. Experientia 36: 1014-1015.

Jesus, C. M., Bertollo, L. A. C. and Moreira-Filho, O. 1999. Comparative cytogenetics in Apareiodon affinis (Pisces, Characiformes) and considerations regarding diversification of the group. Genetica 105: 63-67.

- and Moreira-Filho, O. 2000. Karyotypes of the three species of Parodon (Teleostei: Parodontidae). Ichthyological Exploration of Freshwaters 11: 75-80.

Jorge, L. C. 1995. Estudos citogenéticos comparativos de algumas espécies de peixes da região de Corrientes-Argentina com as do Alto Paraná. MSc Dissertation. Universidade Federal de São Carlos, SP.

Moreira-Filho, O., Bertollo, L. A. C. and Galetti Jr., P. M. 1980. Evidence for a multiple sex chromosome system with female heterogamety in Apareiodon affinis (Pisces, Parodontidae). Caryologia 33: 83-91.

-, - and - 1984. Structure and variability of nucleolar organizer regions in Parodontidae fish. Can. J. Genet. Cytol. 26: $564-568$.

- - - and - 1993. Distribution of sex chromosome mechanisms in neotropical fish and description of a ZZ/ZW system in P. hilarii (Parodontidae). Caryologia 46: 115-125.

Phillips, R. B., Pleyte, K. A., Ert, L. M. V. and Hartley, S. E. 1989. Evolution of nucleolar organizer regions and ribosomal RNA genes in Salvelinus. Physiol. Ecol. Japan 1: 429-447.

Schweizer, D. 1980. Simultaneous fluorescent staining of R-Bands and specific heterochromatic regions (DA-DAPI Bands) in human chromosomes. Cytogenet. Cell Genet. 27: 190-193.

Sumner, A. T. 1972. A simple technique for demonstrating centromeric heterochromatin. Exp. Cell Res. 75: 304-306. 